\title{
THE EU COHESION POLICY IN CENTRAL AND EASTERN EUROPE, A TOOL FOR INNOVATION?
}

\author{
GILLES LEPESANT \\ Research fellow, CNRS-National Center for Scientfic Research, Bordeaux \\ Gilles.Lepesant@free.fr
}

Keywords: cohesion policy, European Union, Central and Eastern Europe

\section{INTRODUCTION}

Globalisation has paradoxical territorial effects. On the one hand, it erodes local and regional particularisms and convinces a large number of elected local officials and citizens that it deprives them of the levers of action they thought they possessed. On the other hand, the change of paradigm in the reflection on territorial development has led to depreciating the simple logic of redistribution in the national framework and increasing the status of endogenous development, local initiative and multiscalar strategies. The process of decentralisation, the erosion of national frameworks through the effect of European construction and the new organisation of the value chain in the firm have in other respects given a new meaning to territorial development policies.

The implementation of the European regional development policy, supposed to work in favour of local and regional authorities, coincides with a renewal of reflection on the role of local actors in the development process. The European Union has the distinctive characteristic of being the area having the most successfully deepened regional integration and, at the same time, granting the highest importance to the reduction of regional disparities. A third of the Union's budget is indeed devoted to regions lagging in development; which is to say a 213 billion euro envelope for the 2000-2006 programming period. With the adhesion in 2004 and 2007 of twelve economies whose GDP was inferior by half to that of the existing Union, the challenges of solidarity and convergence present themselves henceforth in different terms. While the disparities have considerably worsened from the statistical point of view, the Union has not given up reducing them. A 308 billion euro budget has been allocated to regional policy for the 2007-2013 programming period and certain new Member States will have at their disposal an allocation equivalent to 3.5 per cent of their GDP.

The principal challenge for regional policy is to compensate for the lagging behind of the ex-communist countries in physical facilities, notably those concerning protection of the environment and transport infrastructure. Modernisation cannot, however, rest solely on catching up in this domain. It supposes as well an improvement in quality that a policy of innovation and education could make 
possible. In light of the Greek and Irish precedents, it is not yet certain that regional policy can suffice to obtain this objective.

\section{REBUILDING COMPETITIVE INFRASTRUCTURES}

In Central and Eastern Europe, the first years of implementation of the 2007-2013 EU Cohesion Policy were based on the logic of physical infrastructure adequateness than on a more integrated concept of development.

The amount of Pre-Accession Assistance and the amount allocated during the first programming period (limited to 2004-2006) in this area were too feeble for a significant impact to be observed. On the contrary, the amounts planned for the 2007-2013 programming period are substantially larger: nearly 170 billion euros, of which 67 billion for Poland alone. However, nearly 50 billion (which is to say 28 per cent) have been pre-committed to environmental protection, and notably to the sanitation of water supply networks, to meet Community requirements. The other important allocation concerns transport (more than 52 billion) whose impact on economic development depends on numerous variables. While certain countries have devoted important outlays to the healthcare sector (Slovakia) and to e-administration, the amounts directly impacting upon economic development turn out to be modest in many cases.

Indeed, there are observable differences between new Member States. In Slovenia, transports absorb 25 per cent of the Community's envelope, environment 18 per cent (notably for the management and treatment of water), but 28.5 per cent of the funds has been allocated to research and innovation. Efforts in favour of small and medium-sized enterprises (SMEs) are some of the most significant in Central and Eastern Europe (17.6 per cent of the funds). Nevertheless, nearly everywhere the reconstruction of basic infrastructure resulted to be a priority. This redevelopment has not always taken place without difficulty, particularly in transports. The environmental requirements imposed by various Community directives (mainly through the Natura 2000 legislation), persistent differences between national and Community procedures, have in several cases impeded infrastructure projects to be implemented. Above all, innovative practices have not always prevailed.

The European Commission can argue here that the European regulation compels Member States to undertake substantial investments in innovative solutions with lower carbon emissions than road transport. Yet, pending a more detailed inventory than will be possible uniquely at the close of the 2007-2013 programming period, it appears that the Central and Eastern European countries mostly opted for classic solutions such as road construction. Innovative solutions have indeed been implemented by the Czech Republic (in road transport) and by Slovenia (in air transport), more recently by Poland (the 2010 installation of electric-car charging stations in Warsaw), but they remain sparse while spreading rapidly in the West of the continent. The lack of basic infrastructure in several regions may justify the priority granted to the road sector; however, the orientations of mobility policies adopted henceforth by the early Member States (soft mobility, auto train, intermodal transport, etc.) can rarely be found in the planning documents of Central and Eastern European countries and in the projects adopted.

In other domains, this concern for equipping the country by recourse to scarcely innovative techniques, has also taken precedence over the will to innovate. The struggle against the risk of flooding has in this way chosen renovation and construction of dikes that present the disadvantage of accelerating the speed of the current in case of rising water and only transfer the impact of the flood to communes situated downstream. Similarly, in waste management, the construction of incinerators 
(notably in large cities) has often prevailed over the implementation of recycling policies (about 10 per cent of waste is recycled in Central and Eastern Europe as opposed to 50 per cent in the most developed States in the European Union).

The above evidence contributes to highlight a crucial challenge for EU cohesion Policy, i.e. to encourage the Member States to go beyond basic logics of "catching up and to bringing up to level" and to start thinking in terms of more innovative solutions. In the domain of transport as well as in the area of the environment, the time has indeed come in Western Europe of placing greater value on integrated policies that require, in addition to material investments, institutional modernisation and strategic planning capacities. Used intelligently, the European funds allow such options but do not impose them. The Commission does have the legal instruments to encourage the adoption of innovative solutions (notably several directives in the environmental domain), but it has limited power at its disposal, even though the most costly projects require case-by-case examination (the majority of projects are embedded in strategic documents that have been approved upstream).

The global economic crisis that started in 2008 does not seem to have changed things. In the matter of sustainable development, the housing sector is particularly important since it has been one of those most affected by the crisis. It is in addition responsible for 40 per cent of EU energy consumption. The eco-innovative sector is composed mainly of small and middle-sized enterprises (SMEs), a category vulnerable to credit crunch. Moreover, the structural funds in principle furnish new Member States with the means necessary to modernise their housing stock. Regardless, it has been the most advanced States in the area (e.g. the Federal Republic of Germany, Spain and Sweden) that after 2008 have taken the most meaningful measures in favour of energy efficiency, while France was engaging in a significant process of closing the gap.

In Central and Eastern Europe, legislative adjustments have been adopted (Poland, Bulgaria). The Czech Republic has taken accompanying measures within the framework of structural funds (targeting the most modest households as well) and has adopted an action plan in the sphere of energy efficiency. Lithuania and Latvia have brought theirs up to date. Nevertheless, classic technical solutions have been adopted most often. In Poland, energy efficiency has been the objective of only five projects between 2007 and 2009 for a total amount of 7 million euros (European Commission, 2009). The complete plans of action that associate fiscal incentives, training policies and legal framework modernisation, which are probably the most efficacious in the long run, remain the prerogative of some "enlightened" early Member States. Yet, in Central and Eastern Europe the issue of energy efficiency assumes strategic importance for States' security and independence. Coal still plays an important role in the assessment of energy use (it is employed for 95 per cent of electricity production in Poland), and the sole alternative in the short run is an increase in natural gas imports from Russia. Increased recourse to nuclear energy is contemplated in some countries, but over the short and medium term, the role of coal will probably decline only progressively.

In the domains of transport and housing, the constraints imposed by the European Commission (through regulations governing the use of structural funds or certain directives, notably in the energy sector) only marginally facilitate the diffusion of the most innovative solutions in Central and Eastern Europe. It is true that the Commission and the new Member States have a common interest: to ensure a satisfactory absorption rate of the Structural funds within the specified delays (according to the $\mathrm{N}+2$ rule). When all is said and done, sustainable development still remains without much consideration in Central and Eastern Europe even though the structural funds in principle enable the implementation of integrated policies that are responsive at the same time to the necessary technical investments and to the qualifications needs. The recommendations of the Barca Report, 
suggesting the imposition of more binding conditionality and greater collaboration on strategic documents, appear to be pertinent here contingent on an adequate allocation of human resources by the Commission (Barca, 2009).

In the states of Central and Eastern Europe where development often continues to be perceived more as the product of infrastructures than of institutions, of interplay by actors and of investment in human resources, more direct incentives to promote social capital may not be superfluous. Nevertheless, a greater interventionism by the Commission on these subjects would probably encounter the reticence of certain Member States and be undermined by the Commission's lack of human resources. What remains is that, if we represent regional development as a triangle resting on financial resources, quality of governance and the concept of development, the latter is not the object of specific action. By dint of simplifying the framework of regional policy, it runs the risk of being reduced to a simple tool of redistribution. Likewise, the main indicator retained by the Commission in its reflections - namely GDP per capita - would benefit by being more specific and cross-correlated with other indicators, since it presents such a partial vision of territorial dynamics. In this sense, the strictly economic evaluations of the impact of structural funds usually neglect the key role they can play in terms of governance and diffusion of good practice.

\section{ECONOMIC INNOVATION: ANOTHER CHALLENGE FOR REGIONAL POLICY}

Beyond the policies of regional development, the role of innovation in the activity of the firm continues to be crucial for Central and Eastern Europe, confined since the Middle Ages in a peripheral role within the economic geography of the continent. To be sure, during certain periods, notably between the two wars, several Central European regions had a standard of living neighbouring on, even superior to, the living standards in Western European territories. Nonetheless, the diffusion of innovations has always operated from the West to the East, and Central and Eastern Europe has very rarely benefited from a context enabling it to escape from its peripheral status.

While the twenty years of transition since 1989 have made it possible for this area to initiate a process of catching up with the rest of the continent, innovation appears to be indispensable for Central and Eastern Europe to compensate for the erosion of the advantages it had at its disposal since the beginning of the transition, namely: a low labour cost (which is rapidly rising) and a favourable demography. The paradigm that has won recognition since the end of the 1980s according to which "the entrepreneurial economy of knowledge" (Saint-Étienne, 2009) has replaced competition by cost and natural advantages, is henceforth valid for Central and Eastern Europe.

Since the World War II, however, the sense given to the word "innovation" has evolved. During the $1950 \mathrm{~s}$, the term referred to a linear process extending from the scientific discovery to the arrival on the market of the newly conceived product. During the 1960s, this approach did not change radically but emphasis was placed on the demand that had supposedly inspired the innovation and that was important to detect or to elicit. An approach combining these two aspects then resulted in a consensus, and the interactions between the needs of the client and efforts of research were put forward. In the 1980s, the idea was wide-spread that the actors involved in the virtuous innovation process were still more numerous. Next, the technological progress added to the value chain analysis led to attributing greater value to the logics of partnership and interaction within "eco-systems" that are favourable to innovation.

Christian Saint-Étienne (2009) defines the economy of knowledge as "a socio-economic ecosystem that promotes - notably through the action of specialised intermediaries - the interactions 
between entrepreneurs, risk capitalists and investors, researchers, developers production engineers and production operators in order to develop a permanent stream of new products and services capable of satisfying creditworthy demand in a competitive universe". In itself, the word "innovation" consists of a complex reality extending from fundamental research to incremental innovation in the firm, by way of applied research that associates firms and academic institutions, the utilisation of technological progress in the most diverse domains, including the most traditional, or also non-technological innovation in marketing, production organisation and personnel management.

The territory is not at the heart of every innovation process, but adapted territorial strategies foster innovation. Production systems being less hierarchical than they previously were, the local and regional environment of innovation may play a key role in the strategies for implanting production units. Moreover, the diversity of economic fabrics and challenges abolish any pertinence of a unique, centralised innovation policy. The territorial dimension has been emphasised in several pieces of research (notably devoted to "learning regions" or to innovative milieus) that have shown how essential to the development process are immaterial resources (competencies, know-how, qualifications and ways of acting and getting things done). For Björn Johnson and Bengt-Ake Lundvall (1994), "knowledge is the fundamental resource in the contemporary economy, and learning is the most important process". The concept of "learning economy" highlights here the "capacity to learn and to innovate. This capacity has not only a scientific and technological dimension. It implies fertile bonds with universities, research institutions as well as organisational modes and institutional roles" (Johnson and Lundvall, 1994). What emerges here is an approach to the economy founded on learning processes rather than on allocation mechanisms leading to equilibrium.

In this context, far from signifying the end of territories, globalisation makes possible the invention of new forms of territorialisation. Bjørn Asheim (1995) sees the "learning region" as an extension of the industrial district, of which some could say that it suffered from insufficient receptiveness to exterior actors and ideas. According to him, this concept makes it possible to emphasise the risk of path dependence and to transcend the contradiction between functional integration and territorial integration. In an innovation process, the proximity between actors may reduce transactions costs and accelerate informational exchanges through self-reinforcing virtuous dynamics as innovation elicits more innovation. It is nonetheless essential for the "learning regions" to be structured so as to allow a flow of information and contacts between different partners (firms, research centres, financing organisms, etc.).

In this matter, the shoe pinches in Central and Eastern Europe due to the centralising logic of former regimes. Furthermore, certain countries lack regional identities (e.g. Hungary) and/or hesitate to decentralise competencies. The recent drawing of the borders or the presence of minorities (Romania) incite certain governments to avoid regionalisation of their territory (the exception here being Poland). It is not possible to exclude over the medium and long term that the structural funds may reinforce the autonomy of local and regional elites. In the meantime, under what conditions they will be able to promote the emergence of knowledge economies in Central and Eastern Europe it remains to be seen.

\section{LESSONS FROM PREVIOUS COHESION COUNTRIES}

What do the precedents teach us, in Ireland, in Greece or on the Iberian Peninsula? For the 20072013 programming period and by virtue of the priority henceforth accorded to innovation, the link between the cohesion policy and the Lisbon strategy has been reinforced. The States of the EU-15 
are notably under the obligation to invest the major part of their financial allocation in the projects pertaining to this strategy: namely 60 per cent in their regions characterised by the "convergence" objective and 75 per cent in those classified under the "regional competitiveness and employment" objective. No binding objective has been set for the new Member States, but several have established one that is in the vicinity. Bulgaria, Poland and Romania have decided to devote an important share of their resources to the Lisbon strategy R\&D expenditures in the new Member States will be four times higher between 2007 and 2013 than in the preceding programme period (European Commission, 2009). In the negotiations for the 2007-2013 period, the European Commission insisted vis-à-vis the new Member States that a substantial allocation should target applied research. In Slovakia, an effort without equivalence in the Union was granted to promote information and communications technology (ICT).

Beyond this show of infatuation for the Lisbon strategy, the issue of the most appropriate innovation for Central and Eastern European economies remains an open question. Discourse and practice adopted in this matter by the most advanced countries of the Union are not necessarily adaptable to the peripheral countries (Liagouras, 2010). In the case of Greece, the demand for technology is feeble, the economic fabric is dominated by the construction sector and by the service sector (tourism), and SMEs are more penalised by organisational and financing problems than by the rarity of cutting-edge innovations. The country has a renowned scientific base at its disposal, and its indicators, notably in the domain of publication, are flattering, but innovation technology is nevertheless hardly widespread. Indeed, the institutional eco-system in place does not contribute to a proper articulation between academic research and innovation. Yet for George Liagouras, multiplying the technological parks and other such incubators would not be a panacea. The specificities themselves of the economic fabric explain that firms fundamentally have only weak appetence for technological innovation. Reducing innovation to such demand would therefore be pernicious.

Before George Liagouras, Alfred D. Chandler (1990) and William Lazonick (1991) had stressed in their study of economic development in the United States, the Federal Republic of Germany and England that development ensued above all from progress in the organisation of production methods. In our day, in certain domains innovation sensu stricto plays an essential role (biotechnologies, information and communications technology); but as a general rule, the firm is most often subject to the difficulty of articulating market expectations with its competencies. Technological innovation is a component of a vast eco-system. In this sense, the backwardness evaluated by the yardstick of the share of R\&D expenditure in GDP might just as well be the consequence as the cause of the lack of competitiveness. It is therefore essential to understand "innovation" in the broad meaning of the term (Lundvall, 2002) and to include the organisation of production, quality control, distribution methods, marketing and industrial design, all presenting vulnerabilities for firms in countries recently converted to capitalism. It is also necessary for the economies of Central and Eastern Europe to disseminate the know-how of foreign firms throughout the entire economic fabric, even if few among these have implanted R\&D units in the region. To sum up, innovation is required in Central and Eastern Europe on the condition that it won't be limited to technological innovation. In the contrary case, the scientific base of the country could indeed profit from the grants paid to the academic world, but without the economic fabric gaining in competitiveness. Greece is here again illuminating.

In the 1980s, the country decided to reduce its dependence with respect to imports of technology-intensive goods and created the General Secretary for Research and Technology, the GSRT (Liagouras, 2010). Co-financed by the European funds, numerous projects emerged (technological parks, incubators) without generating perceptible impact on firms' innovative capacity. Yet, the idea 
that emphasis should be placed at least as much on the link between the academic world and firms as on fundamental science could be found in all official documents. "If in Greece we had a well-developed private sector with sufficient research capacities, this policy would have generated results. Since this is not the case, the policy benefited corruption more than innovation" concluded Vassiliki Siouti (2004). All in all, it would have been preferable to have invested less in technological innovation and more in the modernisation of firms in the different functions for which they still have a competitive lag. George Liagouras regrets that the rhetoric and advice relating to technological innovation elaborated in the European framework were integrated without taking into account the specificity of the Greek economic fabric.

The Irish case is also worthy of examination to the extent that the Central and Eastern European development model calls to mind the one adopted by Dublin during the years 1980-1990, associating low salaries, attractive taxation and important foreign investment. Patrick Collins and Dimitrios Pontikakis (2006) emphasise the dual character of the Irish innovation system. On the one hand, industrial policy principally occupies itself with disseminating the know-how of locally implanted multinationals to all firms. On the other hand, innovation policy implements the precepts developed in the European framework. For the two authors, one conclusion is obvious: it is the industrial policy applied on the national level that explains how the Irish economy moved up market, much more that the implementation of the Lisbon strategy. While Ireland did receive an appreciable number of foreign investors, a minority of them developed R\&D activities on the spot (one third in 2001, of which roughly twenty accounted for two thirds of the amount invested by foreign firms). Since the 1980 s, calls to revise the development model have multiplied however. As early as 1980, the Telesis Report criticised the excessive dependence on foreign investment and the absence of links between foreign investors and local firms. A national programme initiated in 1985 for the purpose of reinforcing these ties had little result. In 1996, out of the 22,667 Irish SMEs, only 174 were subcontractors of multinationals implanted in the country, and very few belonged to the high technology sector (Breathnach, Kelly, 1999). The successive stages were the creation of a ministry dedicated to science and technology, the publication of a report devoted to innovation policy (the Culliton Report, 1992), then the creation of the Advisory Council for Science, Technology and Innovation (ACSTI) in 1995. The following year, an official report on science, technology and innovation insisted on the necessity of a more endogenous development of the country.

At the beginning of the years 2000, the outcome of these efforts was modest. To be sure, the country is ahead of all the other Member States with respect to the share of high technology products in its exports. The statistics, however, invite prudence since they refer for the most part to exports of computer products but conceal that the technological content of the work done on Irish soil is in general limited. In spite of the effort undertaken, Ireland remains below the EU-27 average public expenditure as well as private expenditure in favour of innovation. As for the number of per capita patent applications, the country is at the end of the queue in the classification of old Member States, and is ahead of only the three other great former beneficiaries of the cohesion policy (Greece, Portugal and Spain).

In the end, the two countries that the literature on the impact of European funds often opposes, the one the model to follow (Ireland), the other the perfect counter-example (Greece), have more points in common than the dominant representation would lead us to believe. Until the 1980s, their innovative capacities were comparable. During the years 2010, the two countries are still among the least innovative in Europe. The divergent economic evolution of these countries from the beginning of the 1980s onward has little to do with innovation. Ireland emphasised training and attractiveness, 
Greece infrastructures. Ireland mobilised numerous institutions such as the Industrial Development Agency (IDA) or the Science Foundation Ireland (SFI) to attract foreign investment in high technology. Whence this perception of a country that has become a pole of competencies in certain high value-added industries, notably in the software industry. In reality, the R\&D effort was borne by the multinationals more than by a national strategy articulated with the economic fabric.

Moreover, while many firms established in Ireland belong to the high-technology sector, the activities they developed there have rarely been high value-added. The country's success results principally from a skilful strategy drawing on an opportunity (access to the extended European market resulting from the adhesion) to attract the FDI (mostly American) due to a well-trained labour force and to renovated infrastructures by means of the European funds. Be it Ireland, Portugal, Spain or Greece, none of these countries has succeeded in elevating itself to the level of the most innovating European economies. Despite dissimilar courses over the 1980s and 1990s, none seems to have constituted the basis of a pertinent development model over the long run. At the beginning of 2010, Ireland and Greece had the most deteriorated public finances of the euro zone and were thus condemned to endure a long period of austerity and anaemic growth.

\section{CENTRAL AND EASTERN EUROPE: A MODEST PLACE IN THE EUROPEAN GEOGRAPHY OF INNOVATION}

The Central and Eastern European context is characterised by industrial economies (for the most part), specialised in low value-added sectors. Yet such sectors have not been the object of specific reflection in the agenda of European innovation policy (Hirsch-Kreinsen et al., 2006, p. 15) even though modernisation through the introduction of external know-how is proving indispensable. To incriminate here European policy would be to forget however that national and regional actors dispose of an appreciable margin of manoeuvre in the implementation of the European funds. The temptation for national and regional actors is nevertheless great to target the numerical objectives of the Lisbon strategy and to draw inspiration from regularly set forth "good practice" recommendations. Yet, these guidelines cannot be considered as such for all regions (Tödtling and Trippl, 2005).

The European instrument panel for innovation set up by the European Commission stresses the backwardness of new Member countries. A topology founded on different indicators leads to four groups (leaders, followers, moderate innovators and catching-up countries). While three new Member States - the Czech Republic, Estonia and Lithuania - are in the next-to-the-last category, all the others are in the last group in the company of a single old Member State, Greece. Evaluated according to the standard of public and private expenditure, Central and Eastern Europe does not appear in a better light. In volume, the public expenditure has never ceased to rise; but when expressed as a percentage of GDP, a widening gap in comparison to the old Member States appears. The financial effort of business entities also lags behind in comparison to other EU countries.

Certainly, other indicators are more flattering. Employment in the R\&D sector is close to the EU-27 average in several Member States. It is even higher in the Czech, Polish, Hungarian and Slovak capitals. However, in 2006 the new Member States still applied for only 166 patents per year, which is 4 times less than Belgium alone and as much as 4,300 times less that the Federal Republic of Germany!

On the scale of the EU, R\&D expenditure by business firms are concentrated in a few territories, ten regions (situated in Germany, Sweden, Finland and in the United Kingdom) alone account for 32 per cent of this spending. As a general rule, the regions of the EU-15 spend 1 per cent of their GNP 
on R\&D investment (GERD - Gross domestic expenditure on R\&D), as opposed to 0.3 per cent in Central and Eastern Europe. No tangible sign of convergence has emerged yet. In the RCE ("regional competitiveness and employment") regions, private firms' R\&D expenditure reaches 1.3 per cent of GDP, which is 4 times higher than in the "convergence" regions. If the tendency at work continues, the gap between the EU-15 and the new Member States should deepen in the course of coming years (with the exception of two regions situated in the Czech Republic - Prague and Moravskoslezsko). Moreover, the RCE regions register 13 times more patent applications than the convergence regions. The public structures supporting innovation are often weak, when not completely absent. In Poland, 50 per cent of powiats (counties) and 75 per cent of communes dispose of no such structure. To sum up, the influx of FDI in Central and Eastern Europe testifies for the attractiveness of the region, contributes to the amelioration of productivity, but is slow in generating visible effects on innovation. Public policies could pick up the baton here by embedding the foreign firms more firmly in the local economic fabric, but only when the firms agree and especially when local, regional and national actors have been able to organise milieus that encourage innovation.

It is in fact important for regional innovation strategies to be based on a precise diagnostic of the economic fabric so that the priorities are not formulated in vague terms. If not, innovation appears detached from other aspects of development even though it should be associated with them. In Poland, the articulation and coordination of regional strategies with the national strategy is often lacking and the links between the other actors of a given region do not always seem solidly established.

Central and Eastern European countries counts several clusters, some of which date back a number of decades. In south-west Poland, the "Aviation Valley" has been the result of an initiative approach pursued by the Polish State between the two wars. Other poles emerged over the course of the communist period. In their study devoted to the ten countries adhering to the EU in 2004, Christian Ketels and Örjan Sölvell (2006) speak of clusters for regions that demonstrate a specialisation in a given sector. Along these lines, they observe that clusters concentrate 58 per cent of total employment in the ten countries under consideration. However, the clusters that satisfy the "triple helix" schema (public actors, academic institutions and private actors engaging in intertwined collaboration) remain rare in Central and Eastern Europe. More often than not, they have little structure and a weak connection to academic institutions. Now, the percentage of firms conducting innovation activities (which is 72.8 per cent in Germany, 41.5 per cent in the whole of the EU-27) does not exceed 27 per cent in Poland and is inferior to that figure in five other new Member States (Eurostat, 2007). On the other hand, numerous Central and Eastern European firms have formed cooperation projects with European partners, notably as a result of the massive presence of foreign investors. On average in the EU-27, 10 per cent of innovating firms have entered into cooperation with European partners. Eleven of the twelve new Member States exceed this percentage, and some of them (in particular, the Baltic countries and Slovakia) appear at the top of the ranking. This good integration is explained in part by the substantial presence of foreign firms.

In Poland, cooperation was initiated between firms and research institutes in certain large cities (electronics in Warsaw and Kraków, pharmaceutics and cosmetics in Kraków and Lódz), but few structured clusters can be counted that give rise, for example, to new vocational training tracks. The special economic zones illustrate here a more general challenge for new Member States. Since the SEZs are destined to disappear progressively in the name of the European policy of free competition, they must structure the conglomeration of activities they made possible. Otherwise, it will be hard to ensure any future embeddedness of the implanted firms within their respective territories. Hungary is a country that put in place a specific cluster policy at the end of the 1990s. The Széchenyi Plan of 
2001 provided notably for specific subsidies while adopting a vague definition of a string of firms that lacked reference to links with research institutes. This initiative also suffered from a lack of budgetary means. It was prolonged in another form after the Plan terminated in 2002, and the support for clusters, since 2004, is integrated into the strategic documents within the framework of the implementation of the structural funds. In 2010, a (long) list of clusters has been drawn up.

The cluster tool has been slowly disseminating in Central and Eastern Europe since the beginning of the transition. The firms driving this process are most often foreign enterprises whose industrial project in the area does not include the intention of developing R\&D activities. Similarly, also the clusters gathering together local firms - frequently belonging to traditional sectors - only rarely have the need and the capacity of developing $R \& D$ activities. The experiments that have been crowned with success are usually a privilege of wealthy regions and/or the extensions of former initiatives, such as the aviation valley in the Rzeszów region. What is more, in this case the cluster is rather a project making it possible to mutualise resources (vocational training notably), to render visible the competencies of the pole and to deepen the collaboration with other European aeronautical clusters rather than to develop R\&D activities.

In the end, while the declared prescriptions at the European level are very often present in the strategic documents, the methodology adopted does not allow to affirm that the new Member States will be able to avoid, in the matter of innovation, the fate of Greece or Ireland. In 2010, a provisional evaluation makes clear that the rate of absorption of sectors devoted to innovation is not very high in several new Member States. In Slovakia, the operational programme dedicated to ICT is currently the least successful one. Finally, the European priorities for innovation are difficult to translate into operational terms and in Central and Eastern Europe the accent keeps being placed on infrastructures (incubators, technological parks, etc.), while organisational and incremental support for innovation in business enterprises is often neglected. The funds are more usefully spent when the following conditions are brought together: strong local partnerships, support for cooperative agreements, for innovative processes rather than for infrastructures alone, and pertinent evaluations of the measures adopted. The examination of precedents leads to believe that a learning process may take place (Musyck and Reid, 2007), certain States having implemented, from one programming period to the next, more ambitious measures than the simple construction of infrastructures, as testifies the example of clusters in Spanish Basque country or also the progressive priority the Czech Republic is giving to the areas of training and education (Blažek and Uhlir, 2007). Besides, needs differ according to the region. Bernard Musyck and Alasdair Reid (2007) put forward the hypothesis that the most disadvantaged regions are not necessarily unreceptive to measures supporting innovation but that in their case, the accent must be placed on the integration of advanced technologies within their traditional activities. One of the difficulties arises from the fact that, in the field of innovation, the enterprise remains the principal actor. The risk is that the least virtuous regions in the sphere of innovation observe their gap with the most innovative regions widen inexorably. This is the scenario highlighted by Clarysse and Ugur Mudur (2001) who class the European regions according to six categories and who note that the methodology adopted to implement the European funds naturally works in favour of the most innovative regions.

\section{SHOULD HUMAN CAPITAL AND SOCIAL CAPITAL BE PRIVILEGED?}

In Central and Eastern Europe, the general consensus is that social capital is weak. The authoritarian nature of the preceding regime and the transformation of social relations as a result of the 
1989 revolutions have led to a dissolution of solidarities, networks and, as a consequence, to an underdeveloped social capital. Everyday practices under the old regime may have sustained distrust in social relations, distrust that is not however to be found in private relations (especially in the family). The absence of confidence among economic actors, the centralised nature of communist regimes and the weakness in the fabric of SMEs may account for the rarity and the need for clusters in Central and Eastern Europe. Certain empirical studies have highlighted along these lines the lack of confidence in economic milieus during the years following the transition (Raiser et al., 2001).

Thus, the question of innovation definitely cannot be summarised by investments in infrastructures and material equipment. In several Member States, the principal gap is less the deficient infrastructures than the shortage of competencies and the lack of confidence among partners, as Jiří Blažek and David Uhlir (2007) point out in the case of the Czech Republic. The influx of private investment may serve as an incentive. The establishment in the Czech Republic of research centres by certain multinational corporations and the links woven between these firms and universities has led to a reorganisation of the Research and Development Council and to the integration in this structure of business representatives.

The success of Ireland probably rested more on the improvements made to the education system than on innovation support. On the demographic level, Central and Eastern Europe is clearly distinguishable from of old Member States by the abundance of its young population. This particularity has benefited them in the course of transition just as it has benefited the development of other countries, notably Ireland and certain Asian countries. It is, however, a window of opportunity that is destined to close due to the collapse in birth rates since the 1980s. For the 2008-2060 period, the new Member States are indeed the subject of the most pessimistic forecasts in the EU-27. Over this period, they will record an important decrease in their population. This observation applies especially to Bulgaria (-18 per cent), Latvia (-26 per cent), Lithuania (-24 per cent), Rumania (-21 per cent) and Poland (-18 per cent). The latter may count 31 million inhabitants in 2060 as opposed to 38 million in 2008 . The corollary of this evolution is that the dependency rate in the new Member States should in increase noticeably and exceed 60 per cent in eight Central and Eastern European countries (Bulgaria, the Czech Republic, Latvia, Lithuania, Poland, Rumania Slovenia and Slovakia).

While the governments of the EU-27 spend on the average nearly 5 per cent of their GNP on education, several new Member States are situated above this average, whereas only two of them (Slovakia and Rumania) devote less than 4 per cent to education. Nevertheless, in PISA (Programme for International Student Assessment) classification, the new Member States are found clearly behind the old Member States. Certainly, the former communist countries can claim to have good-quality general education and an appreciable technical level in numerous educational tracks. Nonetheless, the articulation between the educational system and the needs of the labour market is still perfectible, and the role of one of the structural funds, the ESF (European Social Fund) for the amelioration of labour qualifications remains uncertain.

\section{CONCLUSION}

After two decades of catching up founded on recognised technical competencies, cheap manpower and attractive taxation, Central and Eastern Europe cannot allow itself to play the role of simple assembly platform for western European or Asian manufacturers as it still is, principally in the electronic and automobile sectors. It is essential to develop eco-systems favourable to the economy 
of knowledge so that the region no longer remains a periphery useful to international enterprises for low value-added activities.

The Greek precedent however demonstrates that efficient innovation is not necessarily synonymous with high technology and that it should be articulated with the specific economic fabric in each territory. Examination of the principal former beneficiaries of the cohesion policy also confirms that the structural funds can only play a role if they are integrated into adapted national and local strategies. Favourable eco-systems should be developed on the basis of pertinent strategic choices, financial resources and confidence between the actors. There is the risk however that the commitment of firms remains missing from this eco-system. How can innovation thrive if foreign enterprises do not wish to develop it and if the surviving local enterprises do not have the required capacities? The choice made by Central and Eastern European countries, as previously by Ireland, to buttress the catching-up process to the influx of massive foreign investment raises here questions.

\section{BIBLIOGRAPHY}

Asheim B., 1995, Industrial Disctricts as "Learning Regions". A Condition for Prosperity?, Studies in Technology, Innovation and Economic Policy, Oslo, Université d'Oslo.

Aydalot P., 1987, Les technologies nouvelles et les formes actuelles de la division du travail, dans le Dossier du Centre Économie Espace Environnement, 47.

Bafoil F., Beichelt T., 2008, L'Européanisation d'Ouest en Est, Paris, L'Harmattan, coll. Logiques politiques.

Bailly A., 2009, La science régionale en perspective, Géographie, économie, société, 11.

Barca F., 2009, Agenda for a Reformed Cohesion Policy. A Place-Based Approach to Meeting European Union Challenges and Expectations, rapport indépendant préparé pour le compte de Danuta Hübner, commissaire européen en charge de la politique régionale, Bruxelles.

Barry F., 1999, Understanding Ireland's Economic Growth, Basingstoke, Palgrave-Macmillan.

Blažek J., Uhlir D., 2007, Regional Innovation Policies in the Czech Republic and the Case of Prague: An Emerging Role of a Regional Level?, European Planning Studies, 15 (7).

Breathnach M., Kelly D., 1999, Multinationals, Subcontracting Linkages and the Innovative Performance of Indigeneous Firms: Some Irish Evidence, document présenté lors de l'European Network on Industrial Policy International Conference, Dublin, 9-10 décembre 1999.

Chandler A., 1990, Scale and Scope: The Dynamics of Industrial Capitalism, Cambridge (Mass.), Harvard University Press.

Clarysse B., Muldur U., 2001, Regional Cohesion in Europe? An Analysis of How Public RTD Support Influences the Techno-Economic Regional Landscape, Research Policy, 30 (2).

Collins P., Pontikakis D., 2006, Innovation Systems in the European Periphery: The Policy Approaches of Ireland and Greece, Science and Public Policy, 33 (10).

Commission europeenne, 2009, European Commission Economic Forecast, Bruxelles, Commission européenne.

Crozet M., Lafourcade M., 2009, La Nouvelle Économie géographique, Paris, La Découverte, coll. Repères.

Crozier M., 1986, État modeste, État moderne. Stratégies pour un autre changement, Paris, Fayard.

Eurostat, 2007, Statistiques communautaires de l'innovation, Bruxelles, Eurostat, coll. Statistiques en bref. 
Eurostat, 2008a, Les Entreprises sous contrôle étranger dans l'UE, Bruxelles, Eurostat, coll. Statistiques en bref.

Eurostat, 2008b, The Main Features of the EU Manufacturing Industry, Bruxelles, Eurostat, coll. Statistics in focus.

Hirsch-Kreinsen H., Jacobson D., Robertson P.L., 2006, Low-tech Industries: Innovativeness and Development Perspectives. A Summary of a European Research Project, Prometheus. Critical Studies in Innovation, 24 (1).

Johnson B., Lundvall B., 1994, The Learning Economy, Journal of Industry Studies, 1 (2).

Ketels C., Sölvell Ö., 2006, Clusters in the EU-10 New Member Countries, Bruxelles, Commission européenne.

Lazonick W., 1991, Business Organization and the Myth of the Market Economy, Cambridge, Cambridge University Press.

Lazonick W., 1992, Industry Clusters versus Global Webs, New York (NY), Columbia University, Department of Economics.

Lepesant G., 2009, Géographie de la crise en Europe centrale, Les Études du CERI, 159.

Lepesant G., 2001, Géographie économique de l'Europe centrale, Collection Références, Presses de Sc-Po.

Liagouras G., 2010, What can we learn from the failures of technology and innovation policies in the European periphery?, European Urban and Regional Studies.

Linden G., 1998, Building Production Networks in Central Europe: The Case of Electronics Industry, Working Paper, 126, Berkeley (Calif.), University of California, Berkeley Roundtable on the International Economy (BRIE).

Musyck B., Reid A., 2007, Innovation and Regional Development: Do European Structural Funds make a Difference?, European Planning Studies, 15 (7).

Raiser M., Haerfer C., Nowotny T., Wallace C., 2001, Social Capital in Transition: A First Look at Evidence, EBRD Working Paper, 61.

Rugraff É., 2010, Foreign Direct Investment (FDI) and Supplier-Oriented Upgrading in the Czech Motor Vehicle Industry, Regional Studies, 44 (5).

Saint-Etienne C., 2009, Mobilisation des territoires pour contribuer à la croissance, Rapport à Monsieur le Président de la République, 29 juin 2009, Paris.

Siouti V., 2004, Lack of Money, Research Stops, Kyriakatiki Eleftherotypia, 4 April 2004.

Tödtling F., Trippl M., 2005, One Size Fits All? Towards a Differentiated Regional Innovation Policy Approach, Research Policy, 34 (8).

Veltz P., 2008, La Grande Transition. La France dans le monde qui vient, Paris, Seuil.

Veltz P., 1999, Territoires innovateurs: de quelle innovation parle t-on?, Revue d'économie régionale et urbaine, 3 . 
http://rcin.org.pl 